\section{Revolutionary birthdays}

SIR - Michael Holmes (Nature 373, 468; 1995) points out that, among 19 physicists who took an early position on relativity and 28 biologists who took an early position on evolution, 80 per cent of the former and 92 per cent of the latter were born in the winter months (defined by him as including the period from October to April). Holmes assigns the difference to seasonal differences in nurturing. I assign it to Christmas.

For a child born during the summer months, the first Christmas is a phantasmagorical experience, with all those lights and sounds just when the senses begin to register. That experience is denied to children born during the winter months, either because it is too early for them to enjoy the proceedings or because they are born after Christmas. By the time the next Christmas comes along, they have already experienced one full summer, so the sights and sounds of Christmas lose much of their impact. As a result, summer-born children, impressed by Christmas, tend to grow up along more traditional lines and to be reluctant to embrace such devilish stratagems as relativity and evolution. In contrast, winter-born children, impressed more by nature with all its wonders and less by Christmas with all its dogmas, are more open to innovation, whether scientific or otherwise.

This conclusion is supported by the observation that 100 per cent of US presidents who held office in the eighteenth century were born in the winter months, compared to 66 per cent in the nineteenth century and 44 per cent in the twentieth century, paralleling the change of the United States from a revolutionary society to a bastion of traditional values.

All of the above is of course a paean to the glory of small samples, which are wonderfully user-friendly in offering strong support to untenable theories.

Cesare Emiliani

Department of Geological Sciences, University of Miami.

Coral Gables, Florida 33124, USA

\section{Discriminatory Frontier policy}

SIR - I wish to protest at the discriminatory policy of the Human Frontier Science Program (HFSP) regarding project funding for foreign nationals working in the programme's member states. In a recent full-page advertisement in Nature (4 May) the HFSP called for applications for grants "for basic research (up to 3 years) carried out jointly by research teams in different countries. The principal applicant must be from one of the eligible countries." This statement is explicitly clarified in the HFSP's Guidebook and Application Form for Research Grants. Being from one of the eligible countries “... is defined as being a national (not a permanent resident) of one of these countries..."

This definition is needlessly restrictive and is contrary to the tradition of free movement of research scientists. Although I work in Sweden, am employed by the Swedish Medical Research Council, receive funding from Swedish bodies, educate Swedish students and pay Swedish taxes, I am nevertheless ineligible to apply for an HFSP research grant as "principal applicant" because of my Australian citizenship.

The objectives of the HFSP emphasize the international nature of the programme and its support for younger researchers. But young researchers are notoriously mobile. Thus it would seem more in the spirit of these objectives if the HFSP eased its citizenship restriction for principal investigators. There must be many other researchers in HFSP member states, particularly the United States, who find this restriction unfair.

Michael Lardelli

Department of Developmental

Neuroscience,

Uppsala University,

Box 587, BMC,

75123 Uppsala,

Sweden

\section{Science in verse}

SIR - Skill with words is not confined to those educated in departments of English, and the resources of metre, rhyme and its related tricks are open to everyone. There seems to be no reason to suppose that the propositional space, the set of all possible sentences in a language, needs to be divided between science and sacrosanct poetry, as I. A. Richards once famously proposed. Instead we can say that there is a continuum between more and less rigorous statements, with the looser, funnier or more pompous end taken by verse which normally, but perhaps not necessarily, maximizes its formal elegance and humour or dignity at the cost of its rational strength.

The literary world still jealously guards its vatic prerogatives, but the numbers of readers and the standards of reading diminish year by year, which is hardly surprising given the minimal intellectual and hence imaginative stimulation of the product. Is poetry, then, dead? By no means, it is only a rhetorical technique and may be transferred to any group of thinkers that chooses to take it up. I am convinced that this transition is already taking place, and that there is a great deal of verse being generated by scientific workers and those interested in their ideas.

Your readers are invited to submit material or make recommendations for an anthology of verse and poetry related to science to be edited by Professor Masashi Suzuki of Kyoto University and myself.

Parodies, occasional vers de laboratoire, anonymous limericks culled from benches, and bitter couplets scribbled on conference programmes are as acceptable as deep night thoughts on the self and its genome, or the place of the carbon atom in our mysterious Universe. Mnemonics connected with any scientific matter would be most welcome.

Submissions should be sent to me by post, fax or e-mail. Texts may be sent on disk, or as attachments to e-mail, in the form of text files or as files compatible with the following Macintosh word processors: Microsoft Word, WordPerfect, WriteNow or Nisus Writer.

\section{John Constable}

Department of International Culture, Facuity of Integrated Human Studies, Kyoto University,

Yoshida Nihon-matsu-cho,

Sakyo-ku, Japan

fax: +81757536647

e-mail john@ic.h.kyoto-u.ac.jp.

\section{Street names}

SIR - Street names are too mundane a matter for Nature, but they perhaps reflect science policy and/or demeanour.

W. F. Bynum begins his review of Private Science of Louis Pasteur (Nature 375, 25; 1995): “...when French schoolchildren were asked which historical figure has done most for France, 48 per cent named Louis Pasteur.... In no other country would such a poll have thrust a scientist in pole position."

In France, there is no city worth mentioning lacking a street, boulevard or place "Pasteur" - not to mention Berthollet, Monge, Cassini, Lavoisier, Laplace and so on. Italy names streets after Galvani and Volta. Such countries also name streets after artists and other eminent people.

Does any English city have a Newton or Darwin street or - perhaps with the exception of Stratford-on-Avon - a Shakespeare Square? Where is Turner or Gainsborough Road in London?

\section{Benarie}

20 Bd Jean Pain,

3800 Grenoble, France

\section{Correspondence}

Letters submitted for Correspondence should be typed, double-spaced, on one side of the paper only. 